\title{
Bipolaridade simbólica no Museu Histórico Abílio Barreto
}

\author{
Symbolic bipolarity at the Abilio Barreto Historical Musem
}

\author{
Luiz Alex Silva Saraiva ${ }^{1}$ \\ Ana Maria Alves Machado²
}

\section{Resumo}

Este artigo discute as implicações da coexistência de duas matrizes simbólicas no Museu Histórico Abilio Barreto (MHAB), localizado em Belo Horizonte. No MHAB existem duas matrizes simbólicas concorrentes desde a sua fundação, com inúmeras implicações diretas, como a duplicação dos artefatos históricos, dos espaços físicos e das mensagens dirigidas à população.

A pesquisa foi feita por meio de investigação documental em diversos arquivos da cidade de Belo Horizonte, em jornais do acervo da hemeroteca local, em livros, álbuns, folders e em panfletos editados pela Associação dos Amigos do MHAB e, também, no acervo pessoal da sobrinha de Abílio Barreto. A análise dos dados se baseou na análise do discurso da permanência ou não da proposta original de Abilio Barreto para o MHAB. A conclusão foi de que as matrizes simbólicas de uma organização trazem os signos e símbolos que Ihes são peculiares para o cotidiano organizacional.

Um alerta aos gestores é quanto ao fato de que lidar com um ambiente que é inteligível não significa que ele seja homogêneo. Quando a homogeneidade se apresenta, é mais provável que, de alguma forma, os significados associados pelos indivíduos que compõem aquele contexto tenham achado outros caminhos para se manifestar, não se resumindo a administração, portanto, a técnicas gerenciais.

Palavras-chave: simbolismo; bipolaridade simbólica; museus.

\section{Abstract}

This paper discusses symbolical implications of coexistence of two symbolical sources at Abilio Barreto Historical Museum (ABHM), located at Belo Horizonte, Brazil. At ABHM exist two concurrent symbolical sources since foundation, with a lot of implications, as the duplication of historical artefacts, physical spaces, and messages to the population. The research was made through documental investigation in files of Belo Horizonte, besides local library newspapers collection, books, albums, folders and pamphlets edited by the ABHM Association of Friends, besides Abilio Barreto's niece's personal collection. Data analysis was based on the discourse analysis of maintenance or not of Abilio Barreto's original proposal for ABHM. We concluded that symbolical sources of an organization bring for the organizational day-by-day, signs and symbols always peculiar to them. An alert to managers is that dealing with an intelligible environment does not mean that it is homogeneous. When homogeneity comes, it is more probable that, anyway, meaning associated by individuals of that context had discovered other ways of expression. Management, therefore, is not only about managerial techniques.

Keywords: symbolism; symbolic bipolarity; museums.

\footnotetext{
${ }^{1}$ Doutorando e Mestre em Administração pelo Centro de Pós-Graduação e Pesquisas em Administração da Universidade Federal de Minas Gerais -CEPEAD/UFMG. Vice-Diretor da Faculdade de Ciênaias Administrativas e Contábies da Fundação Comunitária de Ensino Superior de labira - FUNCESI. Endereço: Av. Protásio de Oliveira Penna, 360, ap.101 - Buritis - Belo Horizonte - Brasil - CEP: 30573360 - E-Mail: lassaraiva@uol.com.br ${ }^{2}$ Mestre em História pelo Programa de Pós-Graduação em História da Faculdade de Filosofia e Ciências Humanas da Universidade Federal de Minas Gerais.. Professora
da Fundação Comunitária de Ensino Superior de labira - FUNCESI. Endereço:Rua Içá, 717 - Renascença - Belo Horizonte/MG - Brasil - CEP: $31130-070$ Email: vitorana@superig.com.br
}

Artigo recebido em julho de 2006 e aceito para publicação em agosto de 2006 


\section{Introdução}

A dimensão simbólica de uma organização diz respeito ao que está além dos seus elementos racionais. Referese aos complexos processos de interação humana no meio organizacional, à maneira como seus membros desenvolvem uma história - a partir de um ponto de partida comum, que é a própria organização - para suas interpretações do ambiente que os circunda. Embora poucos autores salientem tratar-se de um processo que dá margem à pluralidade (CAVEDON; FACHIN, 2002; CAVEDON; FERRAZ, 2004; RODRIGUES, 1996, 1997), na maior parte dos estudos da área predomina a tendência de caracterizar o universo simbólico organizacional como algo unificado e coerente, que de alguma forma traduz uma relação com o sistema formal da organização. Considera-se, entretanto, que essa visão empobrece a compreensão das formas pelas quais o simbolismo organizacional se apresenta. A existência de sistemas simbólicos concorrentes numa mesma organização, frutos de matrizes simbólicas distintas, ainda é pouco explorada pelos estudos organizacionais brasileiros.

Se em organizações com características ortodoxas, tratar da questão simbólica requer um certo esforço no sentido de observar, analisar e interpretar artefatos e outros elementos organizacionais não-racionais para compreender as peculiaridades daquele contexto, o que dizer então de ambientes organizacionais culturais constituídos em torno da iniciativa deliberada de levarem seus consumidores a uma determinada experiência simbólica? Estamos nos referindo especificamente aos museus, organizações criadas essencialmente para evocar lembranças nos visitantes, por meio de uma seleção específica de artefatos e signos. Sua dinâmica implica a existência de uma matriz simbólica definida, de onde emanam, de uma forma mais ou menos articulada, os significados que devem ser atribuídos aos signos expostos.

O que dizer então de um museu onde não há apenas uma, mas duas matrizes simbólicas que se confrontam diariamente há mais de meio século? É isso o que este artigo se propõe a discutir: as implicações simbólicas da coexistência histórica de duas matrizes simbólicas no Museu Histórico Abílio Barreto (MHAB), localizado em Belo Horizonte.

\section{O simbolismo nas (e das) organizações e a questão do imaginário}

Intencionais ou não, os distintos signos existentes no ambiente das organizações caracterizam (em maior ou menor grau) as possibilidades simbólicas, não apenas na produção organizacional, mas na "venda" (e no consumo associado) de símbolos das organizações aos seus consumidores. À medida que estes interpretam as mensagens apresentadas, constroem, na sua interpretação, um significado (BULGACOV; BULGACOV, 2002) de certa forma sugerido pelas organizações. Lazzarato (2004) sustenta que as empresas não criam bens ou seus sujeitos (trabalhadores e consumidores), mas o mundo no qual estes existem, o que abre caminho para o estudo das particularidades do simbolismo em organizações culturais.

Não obstante os desafios relacionados a um campo em sedimentação, a abordagem simbólica mostra-se como uma promissora forma de encarar as organizações, especialmente, por partir do pressuposto de que, como diz Lazzarato (2004, p.202), o capitalismo não é apenas um modo de produção, mas "uma produção de modos". Essa visão considera que, como as ações humanas não operam num vácuo, são (re)interpretadas continuamente à luz das referências dos indivíduos, que lhes associam significados, transformando, assim, signos em símbolos, à medida que os interpretam à luz de referenciais próprios para determinado grupo (LEACH, 1976).

A construção simbólica produz camadas de sedimentação onde são acrescentadas novas significações às originais, "mantendo-se um sentido permanentemente atual, sem que com isso resulte na eliminação ou na superação dos elementos anteriores, mas compondo com eles uma significação plural, no sentido atual e igualmente permanente." (CASTRO, 1991, p.117). Como colocam Boudon e Bourricaud (1993, p.491), "toda sociedade só se estabelece e só subsiste se chegar a se constituir como comunidade simbólica". Nesse sentido, "o símbolo pertence a estruturas ideais que lhe são próprias e que se inserem em relações 'quase-racionais', não sendo possível submeter a lógica própria do simbolismo à ordem de uma lógica formalizável” (CASTRO, 1991, p.118). 
Seguindo essa linha de raciocínio, isso significa que não se pode separar o simbolismo social do processo de comunicação de uma comunidade, já que este se baseia num núcleo de significações relativamente estáveis e univocamente compreensíveis por qualquer um dos seus membros, ao mesmo tempo em que varia segundo a forma e o conteúdo próprios da comunicação. Tal variabilidade em processos comunicacionais, precisamente por não ser nem estritamente conceptual e nem sequer estritamente verbal, dá margem a inúmeros malentendidos. Como a dimensão simbólica prescinde da interpretação, o conceito a que toda palavra está ligada pode ser tomado pelo que ele denota ou pelo que conota (BOUDON; BOURRICAUD, 1993; CASTRO, 1991).

Como fenômeno basicamente psicossocial - uma vez que há interpretação, no nível individual, de signos compartilhados pelos membros de uma comunidade - Bordieu (2000) sustenta que o que faz com que toda sociedade seja automaticamente simbólica é a diferença no comportamento de seus membros. O simbolismo, assim, também é um fenômeno social, "uma ordem de fenômenos (práticas e crenças) que se podem qualificar de objetivos, no sentido de que instituem entre os membros da sociedade uma autêntica comunidade." (BOUDON; BOURRICAUD, 1993, p.490). O único sentido que seria pertinente nesse caso, é que toda sociedade define uma ordem de fenômenos compreensíveis, isto é, com significado - pelo menos para seus próprios membros. Por mais estranho que possa parecer à primeira vista, a qualidade de objetividade dos fenômenos da esfera simbólica a que se referem Boudon e Bourricaud (1993) diz respeito aos aspectos reais ou racionais formados a partir da experiência compartilhada de significados entre os membros de uma comunidade. Em outras palavras, a funcionalidade da vida social se deve à rede de significados - que como bem coloca Castro (1991, p.120), "não se prende a uma dada versão do real" - oriunda do simbolismo social.

Captar o simbolismo de uma sociedade (ou grupo social) é captar as redes de significações que ela carrega, constrói e atualiza em suas práticas. Freitas (2000, p.49) sustenta que "a maneira pela qual uma sociedade (ou grupo) se vê, o que ela define como seus problemas, a relação que estabelece com o mundo e seu lugar nesse mundo só podem ser compreendidos e construídos porque a sociedade (ou o grupo) é capaz do imaginário." Ela continua, dizendo que,

o imaginário é o "local" por excelência do projeto a construir, do mundo melhor, do sonho, da fantasia, do desejo. Esse lugar de origem, ponto de partida de todas as significações, encontra-se no imaginário que é compartilhado pelos membros de uma sociedade ou de um grupo social. Ele precisa do simbólico para se manifestar. $O$ indivíduo social é, em todas as suas expressões, valorações, definições e manifestações, perpassado pelo imaginário e suas representações. (FREITAS, 2000, p.48)

Da mesma forma que o simbolismo assenta-se sobre componentes objetivos, Maffesoli (1978, p.69) defende que o imaginário "não seria um pensamento separado do real, mas uma atitude que pratica uma certa defasagem, 'paralelamente' ao que seria mais metodológico do que sistemático e que permitira ao mesmo tempo a crítica e a realização do possível". Rodrigues (2000, p.3) tem a mesma opinião, de que "o imaginário oferece a forma de organizarmos nossa prática cotidiana, [...] o modo como entendemos a nós mesmos e o mundo vivido antes mesmo de ser aprendido e formulado". Nesse sentido, "todo grupo tem um eu próprio, imaginário, que o torna vivo e que se manifesta através da ilusão grupal” (FREITAS, 2000, p.50).

A esse respeito, Maffesoli (1978, p.70) argumenta que é vazia de sentido a distinção entre o imaginário e a realidade, "fruto de uma atitude estreita que não pode compreender a dinâmica do vir-a-ser". Como o "homem é um ser que tem a capacidade de criar imagens, de imaginar, ele é, portanto, um ser influenciado por seu imaginário, seu pensamento, e suas ações não escapam ao princípio constitutivo da imaginação humana." (RODRIGUES, 2000, p.1). Por isso este autor sustenta que é no imaginário que estão incrustados diversos elementos do real, e "é nesse sentido que o sonho é o indicador dinâmico do real, uma vez que também ele permite a unificação social em torno de um projeto coletivo." (MAFFESOLI, 1978, p.73). Já que não são aspectos antagônicos a realidade, o simbolismo e o imaginário, nada mais natural do que observar suas interfaces tendo como pano de fundo as organizações culturais no capitalismo. 


\section{Capitalismo, simbolismo e organizações culturais}

Parece acertada a perspectiva de Lazzarato (2004) de que atualmente presencia-se uma transformação radical na natureza das organizações, que estariam se tornando essencialmente simbólicas. Por conta do aumento do papel da mídia e da disseminação da cultura popular, como coloca Wood Jr. (2000, p.27), "a simbolização constitui processo irreversível" para o qual caminham, com maior ou menor velocidade, praticamente todas as organizações, no que, em certo sentido, também se acredita. Compreender a essência simbólica das organizações (ALVESSON, 1990; ALVESSON; BERG, 1992), portanto, é um objetivo não apenas adequado do ponto de vista científico, como também está de acordo com a compreensão da natureza que as organizações parecem gradativamente assumir. Para Boudon e Bourricaud (1993, p.489), é simbólica "a atividade de substituição que oferece satisfações compensadoras, na falta dos resultados esperados ou prometidos", de maneira que o simbolismo assume um papel cada vez mais importante num contexto organizacional que já resolveu - pelo menos institucionalmente - a questão da recompensa aos empregados.

Quando o simbolismo presente nas organizações se encontra em um contexto capitalista, a situação se torna complexa, principalmente, porque este é um momento histórico específico em que se pode verificar uma tendência reducionista de atribuir ao econômico importância sobre todas as coisas. Além do uso mais ou menos implícito que as organizações fazem das estruturas psíquicas dos indivíduos (FREITAS, 2000), "tudo no capitalismo conspira para preservar a ordem simbólica do sistema." (SAHLINS, 1976, p.293)

Não obstante o simbolismo ser ligado intrinsecamente à natureza humana, o capitalismo contemporâneo descobriu aí um filão a ser explorado: a identificação simbólica dos indivíduos com a organização (LIMA, 2004), a fim de aumento das possibilidades de resultados. Como coloca Chauí (2000, p.12), "no capitalismo, não há coisa alguma e pessoas alguma que escape da condição de mercadoria, não tendo como ser retirado do circuito da circulação mercantil". A esse respeito, Baudrillard (2000, p.134) alerta para o perigo do discurso "anti-sedução", pois sua legitimidade está baseada na estratégia de sedução que o sustenta, que torna os diversos atores organizacionais tanto vítimas quanto produtores de uma "transfiguração das coisas em aparência pura".

A manipulação de símbolos pode incrementar sensivelmente a imagem do negócio, bem como dos produtos e serviços comercializados. Basta investir na mobilização da subjetividade dos empregados num primeiro momento - o que não é fácil, evidentemente - e, num segundo momento, na subjetividade dos consumidores (CLARKE III; MICKEN; HART, 2002; DERBAIX; DECROP; CABOSSART, 2002; MAXWELL, 2003). Tal empreitada, contudo, não é simples. Além das dificuldades de reconhecimento e interpretação dos signos - a fim de que estes venham a tornar-se símbolos, objetos de uma interpretação social comum (LINSTEAD; GRAFTON-SMALL, 1990) -, há outro problema: a manipulação de símbolos esbarra na possibilidade de interpretação dos signos de forma diferente da que foi planejada pelos analistas simbólicos (WOOD JR., 2000). Em outras palavras, mesmo que haja muita informação ou uma grande quantidade de especificações sobre como determinado aspecto precisa ou deve ser interpretado pelos indivíduos (membros da organização ou não), nada garante que suas subjetividades serão mobilizadas (ou alinhadas, para usar uma expressão oriunda da área de estratégia empresarial) para compor o cenário visualizado pela organização. Se esse problema existe em qualquer organização - aliás, é sempre um empecilho para a efetividade das ações da área de comunicação, por exemplo -, nas organizações culturais tal situação assume contornos dramáticos.

Em organizações culturais, não obstante haver um valor de troca para seus produtos, é seu significado que define o seu consumo e desempenho, mais do que qualquer outro fator a eles associado (LAWRENCE; PHILLIPS, 2002). Como colocam Lampel, Lant e Shamsie (2000, p.263), embora até recentemente as práticas gerenciais e organizacionais dessas organizações parecessem anômalas, é cada vez mais difícil ignorá-las, considerando, principalmente, a "extraordinária influência sobre nossos valores, nossas atitudes e nosso estilo de vida".

As organizações culturais se apresentam como um dos mais promissores campos para os estudos organizacionais, à medida que, como as organizações religiosas (CEDOLA, 2004; WATTANASUWAN; ELLIOT, 1999) ou de mídia (LAMPEL; LANT; SHAMSIE, 2000), caracterizam-se como organizações de 
simbolismo intensivo (WOOD JR., 2000, 2001). Por serem organizações que gerenciam, produzem e distribuem produtos culturais, as organizações culturais diferem dos outros tipos de organização, principalmente, por que sua razão de existir, é, antes de qualquer outra coisa, o consumo dos seus símbolos na forma de significados interpretados pelos consumidores de seus produtos (LAWRENCE e PHILLIPS, 2002). Como salienta Hirsch (2000, p.359), a extensão do conceito sugere

Um continuum que vai do uso cultural ao utilitarista para muitos consumidores de produtos, possibilitando abranger características adicionais como comida de gourmet, esportes profissionais e orquestras sinfônicas.

As organizações tradicionais, com uma lógica centrada na produção e não no consumo (LAMPEL; LANT; SHAMSIE, 2000; LAWRENCE; PHILLIPS, 2002;), divergem das organizações culturais já a partir da concepção. A premissa é a de que por existirem com, pelo e para o consumo de bens culturais, as organizações culturais merecem um olhar mais atento às suas peculiaridades. Para entendê-las, portanto, é preciso partir da natureza não-utilitária de seus produtos (LAMPEL; LANT; SHAMSIE, 2000).

As organizações culturais se inscrevem num quadro que se baseia na produção de algo que seja não apenas passível de interpretação pelos consumidores, mas, principalmente, adequado às suas necessidades de consumo simbólico (HIRSCH, 2000). Como sustentam Lampel, Lant e Shamsie (2000, p.268), "seus produtos evocam intensamente experiências particulares, e eles fazem uso de valores e aspirações que não são utilitaristas e nem comerciais". A criação de produtos culturais que não atendam às expectativas ou as superem pode gerar distorções particularmente difíceis de serem gerenciadas. Tal questão, contudo, não impede que haja tentativas sistemáticas de instrumentalização das ações das instâncias simbólicas, a fim de configurar quadros "mais adequados" ao desenvolvimento das atividades organizacionais. Como foi dito anteriormente, ainda que não existam garantias de que os símbolos sejam interpretados com o significado desejado pela organização, as tentativas são sistemáticas nesse sentido, como no caso dos museus.

\section{Museus, memória e intencionalidade simbólica}

Na idade do efêmero e do consumismo, o museu conserva para amanhã. Aí residem sua singularidade, seu papel e seu objetivo. Mas essas insubstituíveis coleções de objetos originais bi ou tridimensionais são tão inúteis ao visitante quanto um livro nas mãos de um analfabeto, se não forem expostas de modo a serem compreendidas ou amadas. (GIRAUDY; BOUILHET, 1990, p.14)

De acordo com a perspectiva apontada por Giraudy e Boulhet (1990), os museus surgem como espaços favoráveis ao reconhecimento da memória como elemento que evoca contextos passados. Sua natureza orientada pelas variadas intenções que permeiam a atitude de resgate do passado, busca trazer para o presente um passado intencionalmente recuperado. A memória significa para o museu histórico um campo privilegiado de ação e reflexão.

Os museus são ambientes propícios ao recolhimento de objetos evocadores de contextos passados (THANEM, 2001). Na seleção, organização e natureza de seu acervo há o esforço de resgate de um passado que está sendo procurado. Embora os museus sejam uma reconstituição necessariamente mosaica de contextos, cada museu tem a capacidade de enfatizar uma idéia nuclear que o situa num campo ideológico definido.

A natureza dos museus tem sua definição orientada pelas mais diversas intenções que permeiam a atitude de resgate do passado, objetivando que no âmbito do presente o pretérito tenha a ressonância almejada. A memória dos museus é uma das formas de percepção dos elos que atam o passado ao presente. A memória é, pois, o olhar do presente lançando-se sobre o passado, reconhecendo nele algo que faça parte de um tempo relativo à própria anterioridade ou a alguma outra da qual se passa a ter idéia. Histórias subjetivas e aquelas que relatam as ações coletivas dos homens em seu espaço social e temporal se redimensionam através da memória (BOSI, 1994). 
Há, por conseguinte, um ponto diferencial no processo de construção da memória. Em primeiro lugar, cabe destacar que a memória faz parte das diferentes linguagens, matéria-prima de suas construções, "vértice do sistema" (LE GOFF, 1984, p.17) identitário de indivíduos e sociedades. Essa relação entre memória e identidade diz respeito ao conjunto de referências materiais e simbólicas que permitem à sociedade reconhecerse como parte de um mesmo universo. Em segundo lugar existe uma relação entre poder e memória. A memória, como forma manipulada de poder, representa o valor da sociedade traduzido nos monumentos públicos. Estes consolidam a ação seletiva da memória e expõem "as manipulações conscientes ou inconscientes que o interesse, a afetividade, o desejo, a inibição e a censura exercem sobre a memória individual, tornando-a uma memória coletiva." (LE GOFF, 1984, p.13)

Podemos definir memória coletiva como um conjunto de elementos estruturados que aparecem como recordações socialmente partilhadas de que dispõe uma comunidade, como forma de alusão à sua própria trajetória no tempo (LE GOFF, 1984). Nesse sentido, tudo e todos se tornam "lugares de memória". A sociedade constrói uma espécie de "patrimônio comum que, seletivamente, acaba residindo em depósitos sociais (arquivos, monumentos, museus)" (CARDOSO, 1997, p.9). Assim, quando se adentra num "lugar de memória", como os representados pelos museus históricos, é possível recompor a relação entre passado e presente. $\mathrm{O}$ velho e o novo devem ser compreendidos juntos como memória histórica, integrando, com suas contradições temporais e espaciais, o imaginário coletivo. Assim, a criação do Museu Histórico de Belo Horizonte (hoje Museu Histórico Abílio Barreto - MHAB) refere-se, antes de tudo, à criação de um lugar de disponibilização de objetos de natureza diversa, capazes de estabelecer vínculos com o passado, ajudando assim a viabilizar um espaço de preservação da memória da cidade.

\section{Metodologia}

Neste artigo, não se compreende a metodologia apenas como tecnologia, ou seja, como um aglomerado de técnicas apropriadas à execução de um trabalho científico. O entendimento é o de que é preciso que tais métodos sejam precedidos por discussões nos níveis ontológico, epistemológico e teórico. Ontologicamente, a visão em que este artigo se baseia considera a perspectiva nominalista, de cunho subjetivista e que parte do pressuposto de que as palavras conferem sentido à realidade (BURRELL; MORGAN, 1979). Em termos epistemológicos, este texto se situa numa visão anti-positivista, já que não está preocupado com a identificação de padrões para entender o funcionamento do mundo, pois, pelo contrário, acredita que a realidade é uma construção relativa que só pode ser compreendida do ponto de vista dos envolvidos com o objeto observado (BERGER; LUCKMANN, 2005). Como decorrência, assume-se uma visão voluntarista da natureza humana já que, em última instância, cabe aos homens definirem seu caminho - e uma metodologia ideográfica, que considera a subjetividade dos envolvidos com a situação estudada (BURRELL; MORGAN, 1979).

Este artigo está ancorado teoricamente em diversas áreas de conhecimento, como a história política, a museologia, a sociologia e, naturalmente, os estudos organizacionais. A interface entre essas áreas deu subsídios para a reflexão, análise e interpretação dos dados coletados. Com isso, procurou-se resgatar uma dimensão da história, particularmente daquela iniciada com a fundação do Museu Histórico Abílio Barreto (MHAB) - então Museu Histórico de Belo Horizonte (MHBH) - na década de 1940, contextualizando-a de acordo com uma temática própria dos estudos organizacionais: a do simbolismo nas organizações.

O marco temporal, embora circunscrito a esse período, foi transposto quando foi necessária uma maior compreensão de como se construiu a memória de Belo Horizonte através da guarda e exposição de objetos que perpetuaram sua história. Em função do objetivo desta investigação, análise organizacional de um objeto ligado de forma tão peculiar à história, como um museu, metodologicamente optou-se por trabalhar com um amplo e variado "corpus documental" espalhado pelos arquivos de Belo Horizonte. Fizeram parte deste "corpus documental" o Arquivo Público Mineiro, o Arquivo Público da Cidade, o arquivo do Instituto do Patrimônio Histórico e Artístico Nacional (Iphan) - seção Belo Horizonte, sem contar o próprio MHAB. Completando essas fontes estão jornais do acervo da Hemeroteca de Belo Horizonte; livros, álbuns, folders e panfletos editados pela Associação dos Amigos do Museu Histórico Abílio Barreto. Outras fontes consultadas foram as do acervo pessoal de Dona Lêda Barreto, sobrinha de Abílio Barreto. 
Diante desse elenco de possibilidades metodológicas foi necessário recorrer a diversas formas de análise dos dados recolhidos, na tentativa de captar a complexidade das relações políticas que envolveram a criação de museus no Brasil na década de 1940, tendo como estudo de caso, o MHBH. Como se trata de uma coleta de dados com base em documentos históricos e na história oral, a análise se baseou na observação da permanência ou não da proposta de Abílio Barreto para o Museu Histórico de Belo Horizonte.

O conteúdo coletado foi analisado à luz da continuidade dos posicionamentos do historiador conforme as características atuais do MHAB. Neste estudo, procura-se mostrar que os diversos conceitos, preceitos e normas da museologia vigentes na época da criação do $\mathrm{MHBH}$, embora tenham influenciado sua abertura e funcionamento, não representaram uma camisa de força simbólica para essa organização, permitindo que a condução e a inovação de Abílio Barreto na organização e direção do museu apontassem outros caminhos.

Os dados da pesquisa confirmam que à frente da organização do museu, a figura de Abílio Barreto independentemente das definições no plano nacional do antigo Serviço do Patrimônio Histórico Nacional (Sphan, hoje Iphan) - construiu uma interpretação própria do museu da cidade: suas funções, a articulação entre o prédio e o acervo, a reflexão sobre o papel do museu, definições conceituais importantes etc. Mesmo no contexto autoritário e centralizador do Estado Novo, uma visão revolucionária se instalou, considerando não as glórias de um passado longínquo, mas a memória recente de uma cidade republicana que estava sendo construída.

A idéia de que o povo precisava "se enxergar" e fazer-se presente nessa história foi um diferencial significativo da visão de Abílio Barreto, tão presente que a quantidade de visitantes, um indicativo (mercadológico) de sucesso de um empreendimento como um museu, tem sido expressiva desde sua inauguração.

\section{A cidade de Belo Horizonte ganha um museu - o início do embate}

A história dos museus está intimamente relacionada com a Antiguidade. Desde os primórdios de sua criação, os museus abrigam como objeto de valor o que é antigo, o que mostra o claro distanciamento entre o passado e o presente. Lugares de memória, os museus cumprem o papel de resguardar a história do esquecimento dos homens, ou, como diria Thanem (2001, p.31), de "preservação da sensação".

Resguardar a história do esquecimento dos homens. Esse seria o motivo para construir um museu histórico na ainda jovem cidade de Belo Horizonte, onde a definição de antigo certamente não implicaria a idéia de "tempo remoto", do "que existe desde muito tempo", "velho", como encontrado nos dicionários. Prestes a completar 50 anos, a cidade ganhava um museu para contar sua história ainda embrionária. Cenário de grandes e rápidas transformações que lhe acenavam um destino de metrópole moderna, a Belo Horizonte dos anos 1940 via sua história transcorrer a passos rápidos. Do antigo Arraial do Curral Del Rei quase nada mais restara. A nova capital prosseguia rumo à modernidade. Nesse sentido, a criação de um lugar de memória para a cidade talvez a resguardasse do esquecimento de seu passado. Foi isso que Abílio Barreto percebeu quando cogitou criar um museu para a cidade, junto à administração municipal. Precursor da guarda da memória local, ele sempre demonstrou preocupação e interesse com relação à preservação de objetos evocativos da história do município. Considerado historiador da cidade, muito contribuiu para a valorização de seu passado, seja por colecionar objetos referentes à história local como pela escritura narrativa que buscava recuperar episódios dessa mesma história.

A criação do Museu Histórico de Belo Horizonte foi uma iniciativa de Abílio Barreto e do então prefeito Juscelino Kubstichek pela preservação da memória de Belo Horizonte e do Arraial do Curral Del Rei. Essa iniciativa se inseria num contexto político-cultural de valorização e preservação dos símbolos históricos do país. Esse intuito de evocação da história pátria também impulsionou ações de valorização e preservação da história de localidades. Foi o caso da Belo Horizonte dos anos 1940.

Se por um lado havia o plano de modernização implantado por Kubstichek, por outro, a política nacional estadonovista exaltava a construção de uma identidade nacional, e o fazia, entre outras formas, pela construção de monumentos, o que foi um incentivo para a criação de museus no país, em observância ao movimento das 
correntes de preservação da memória coletiva nacional. Em Belo Horizonte, esse objetivo de preservação e valorização de elementos evocativos do passado conviveu com a trajetória da cidade rumo à modernidade.

Naquele momento da política nacional, a expectativa era a de que a preservação do patrimônio e da memória nacional inspirasse a modernização do país e a valorização da cultura brasileira. Da perspectiva do então ministro da Educação Gustavo Capanema, a identidade da nação a ser construída pela ideologia do Estado Novo deveria se afastar do culto das tradições e do ufanismo patriótico - como era o pensamento de Gustavo Barroso - empreendendo uma idéia de monumento histórico pela qual os valores artísticos identificados na arquitetura inspirassem uma reinterpretação da formação histórica do Brasil. É nesse contexto que se discutiu a criação de um lugar de memória para a cidade de Belo Horizonte. Foi então instituído, pelo Decreto n⿳o 91 de 26-5-1941, a seção de História, anexa ao Arquivo, "como núcleo do Museu da Cidade, a ser instalado na Fazenda Velha, no Córrego do Leitão; competindo à mesma, além da informação sobre tudo o que diga respeito ao passado de Belo Horizonte, a coleta, classificação e conserva de coisas ao mesmo ligadas".

Por essa época, o casarão da Fazenda do Leitão incorporava a idéia de monumento a ser preservado, já que se tratava de um importante exemplar do passado colonial da cidade. Elemento representativo da história do século XVIII, atendia aos interesses e objetivos do Sphan voltados para a iniciativa da preservação de preciosidades artísticas e históricas locais. Entretanto, sua indicação para sede do Museu da cidade, idéia defendida pelo Sphan por reconhecê-lo como único exemplar significativo do passado histórico local, não poupou a administração municipal de uma série de entraves para instituí-lo como espaço de memória da história belo-horizontina, da estruturação do ambiente físico desse espaço à natureza da organização do acervo que deveria constituí-lo. Esse fato sustentou-se no embate de idéias protagonizado por Abílio Barreto e o Sphan, cuja polêmica desencadeada muito contribuiu para estabelecer as peculiaridades que marcariam a configuração do Museu Histórico de Belo Horizonte.

Desde o primeiro momento do empreendimento, havia diferenças entre a visão de Mário de Andrade e a de Rodrigo Melo Franco de Andrade. Enquanto para o primeiro os museus deveriam expressar o valor identitário que representasse a comunidade local, o segundo advertia para o caráter nacional dessas instituições, destinando-se os museus a uma classe social informada - não ao povo - uma elite cultural que dispensa ajuda, podendo até contribuir para o melhor conhecimento da arte no país. De acordo com Londres Fonseca (1997, p.135), tantos os intelectuais (inclusive os modernistas) como os políticos do Estado Novo "entendiam o povo como massa, sem canais próprios de expressão. Mário de Andrade valorizava positivamente o povo, reconhecendo na criatividade das manifestações populares a presença viva e dinâmica de nossas raízes culturais".

\section{O Sphan e a memória do passado grandioso}

A criação do Museu Histórico de Belo Horizonte ocorreu, como já foi dito, concomitantemente com os primeiros estudos de sistematização de coleções no Brasil, época em que surgiram o Sphan e os projetos de preservação do patrimônio histórico nacional, todos frutos de uma conjuntura política conservadora e de forte intervenção oficial - a Era Vargas e o Estado Novo. Formalmente, a proposta inicial do museu era a de colecionar ícones relacionados com a história do extinto Arraial do Curral Del Rei, além de coletar, classificar e conservar objetos característicos do passado de Belo Horizonte. O acervo do museu foi constituído, assim, por coleções de arte sacra, por mobiliário, pinturas, esculturas, objetos do cotidiano e por importante documentação arquivística, bibliográfica, fontes primárias da sociedade que ali se formou, desde os tempos do Arraial Curral Del Rei, passando pela formação da nova capital mineira. A seleção e organização do material que compôs o acervo mostraram-se como ponto em que o passado se cristalizava, permitindo ao observador retomar fragmentos de uma dada época e, ainda, perceber além do visto o que existe como história.

No cenário nacional, o que se classificava como histórico deveria trazer em si marcas de antiguidade, traços de um tempo mais remoto a impregnar a figura dos homens e de seus feitos. Deveria estar, portanto, presente no objeto, relíquia de um tempo, uma aura de revelação de uma história venerável e distante que jamais poderia ser objetivamente tocada pelo presente, pois o exercício de se cultuar exige um estado de encantamento diante daquilo que se oferece como objeto de culto. Assim, homens com suas batalhas, ações e pensamentos, quando 
tocados por um tempo que se amplia criando claras noções de distanciamento podem tornar-se, com maior eficácia, importantes protagonistas de heróicas batalhas, de ações decisivas e autores de pensamentos revolucionários que lhes conferirão a condição de mitos.

Como instituição o museu fazia jus ao discurso museológico do Sphan, sobretudo quanto à sua função de revelação e incorporação do sentimento de pertencimento à nação, visto que, retomando a história da cidade, revelava aos cidadãos belo-horizontinos a sua própria história, promovendo um sentido de identificação entre o sujeito e a cidade, que de alguma forma, ele ajudava a construir. Essa perspectiva tinha como base a mesma idéia que regia as políticas nacionais de preservação e valorização da história do país que buscava apresentar aos cidadãos, através dos monumentos, referências a um passado heróico e glorioso, fruto da ação de homens veneráveis, visando despertar nos mesmos o orgulho patriótico, forma de identificação entre sujeito e nação.

A decisão política de criação do Museu da Cidade de Belo Horizonte, além de uma iniciativa de Abílio Barreto, deve ser considerada no âmbito de uma política governamental estadonovista, da mesma forma que a fundação do Instituto Histórico e Geográfico Brasileiro (IHGB) e do Sphan. Tais instituições, voltadas para o culto das tradições, transformaram a história do Brasil e os museus brasileiros em documentos-monumentos, funcionando como lugares de construção do passado que deveria legitimar a política vigente (CHAUÍ, 2000).

Nesse sentido, o Sphan veio reforçar a atitude de organização da memória num sistema conceitual que refletia a ideologia vigente. Era então implementada oficialmente a criação de instituições voltadas para a preservação de bens culturais evocativos da história nacional, diferente do plano elaborado por Gustavo Barroso, de culto ao passado exaltando seu cunho patriótico através dos feitos de homens ilustres, atribuindo a isso uma perspectiva de monumentalidade, principalmente, nos museus. Para Gustavo Barroso, a idéia de preservação sempre esteve relacionada com a "função prática de amar a pátria". A responsabilidade do museu era fazer brotar nos indivíduos um sentimento nacional. Pelos ensinamentos dessas instituições, o brasileiro deveria aprender a amar e respeitar a pátria (SANTOS, 1996, p.24).

Com relação aos museus e outras instituições culturais, o Sphan - tendo como principal articulador seu diretor, Rodrigo Mello Franco de Andrade - atuou como órgão organizador da cultura, como elo de ligação entre a sociedade e o Estado. Todas essas atribuições fomentaram a missão política dos museus, em conformidade com a política do Estado Novo, ao exercerem um papel político fundamental na construção da nação. Essa mentalidade específica de organização e preservação da história pátria será a mesma que prevalecerá como tônica determinante do modelo de formatação da história de diversas localidades, por meio dos museus municipais.

\section{Abílio Barreto e a memória de "vanguarda"}

Ao propor um projeto de patrimônio nacional, Mário de Andrade lançou mão de uma noção de história predominante no início do século XX, a história factual, centrada nos eventos políticos referentes aos grupos que detinham o poder. No entanto, a política de museus apresentada no projeto foi além dessa prerrogativa, adotando uma postura avançada para a época. Definindo os museus como "agências educativas", ele apostava nos modernos museus técnicos, com ênfase nos ciclos econômicos do Brasil. Esses museus seriam, segundo ele, um contraponto aos museus históricos nacionais, "na medida em que fugiriam à apresentação celebrativa de grandes vultos e feitos". Temas como a extração do ouro, do ferro, a história da imprensa, das locomotivas e muitos outros. Quanto aos museus municipais, seriam implementados museus de cidade, e a seleção e composição de seus acervos deveriam estar de acordo com a identidade local. Dessa forma, o acervo desses museus municipais deveria expressar o valor identitário que representasse a comunidade local e a valorização dada por ela. De acordo com Chagas (1999), a narrativa museológica, nesse caso, deveria surgir do diálogo com a população interessada na constituição dos museus.

Como traduzir a visão portentosa de história - marcada necessariamente por uma extensão considerável de espaço cronológico - num ambiente em que o passado e o presente, separados por linhas tênues, eram ainda elementos tão próximos? Talvez, outra perspectiva de avaliação do objeto histórico fosse a saída. Essa sensibilidade de análise perpassou a atitude de Abílio Barreto como um historiador atento às grandes mudanças 
por que passava a cidade de Belo Horizonte, desde a primitividade do arraial Curral Del Rei à construção de um espaço urbano marcado pela modernidade e pelas perspectivas de progresso. Ali, a memória não urgia certamente de grandes espaços de tempo para fazer-se, já que a ação de um progresso voraz parecia acelerar o tempo. A história se fazia célere e apenas olhos bastante atentos perceberiam a sua dinâmica.

O fato de ver entre peças de acervo de museus - instituições geralmente afeitas ao culto à tradição e à monumentalidade -, objetos que relatam a história de um ponto de vista cotidiano e informal, reforça a idéia inovadora presente no Museu Histórico de Belo Horizonte. Como mentor da criação dessa instituição, Abílio Barreto elegeu para ela um sentido novo em relação à concepção museológica da época. Narrar a história da localidade limitando-se à retomada dos primórdios de sua existência, o Curral Del Rei, passando pela construção da então nova capital e por sua rápida transmutação em moderno e progressista cenário urbano seria, para Abílio Barreto, restringir sua história a um percurso meramente retilíneo, negando os vieses e entrelinhas que lhe concediam valores mais amplos de realidade.

Fundar a nova capital significou romper com o período colonial e inaugurar os ideais republicanos, trazendo para o estado e sua capital novas funções administrativas e, principalmente, representativas (ANDRADE; MAGALHÃES, 1998). Tal rompimento, em muitos dos casos, passou pela demolição do antigo, o que não só ilustrava a nova ordem social como também relegava ao esquecimento parte de uma história que não precisava ser lembrada. Assim, dessa perspectiva, a cidade que surgiu - deixando poucos vestígios do passado - precisou da arquitetura para criar referências nas quais as pessoas se reconhecessem.

A invenção da nova capital também inventou uma nova tradição igualmente construída e formalmente institucionalizada. Destruídos os suportes materiais da memória local com o aniquilamento das construções do antigo arraial, em seu lugar foram constituídos novos valores e símbolos ligados à práxis coletiva, ajustando-a a um novo espaço evocador da modernidade.

A construção da nova capital propiciou a criação de suportes de memória, onde se acomodaram os repertórios selecionados no tempo. Nas imagens que perpetuaram as lembranças do arraial, os curralenses encontraram um sentido para viver o presente, projetar o futuro e se inserir no tempo. A Belo Horizonte do final do século XIX guardou segredos incrustados nas contradições do antigo e do novo que fazem o repertório da memória construída.

A política administrativa municipal previa então para a cidade um projeto de urbanização cuja tônica apontava para um efusivo desejo de progresso. O destino de metrópole, a ser alcançado em prazo relativamente curto, teve seu ritmo marcado pelo trabalho incansável de operários movimentando-se entre máquinas e andaimes, manuseando materiais e ferramentas e, desse movimento, fazendo explodir aos olhos o nascimento de uma nova cidade. $\mathrm{O}$ surto vertiginoso de progresso garantiu, assim, à nova cidade já nascer com uma história. $\mathrm{O}$ sonho urbano de uma capital moderna, planejada e sem marcas do passado negava as antigas tradições, para reinventá-las na ambição de fundar o novo, atribuindo-lhe valor e significado. Contudo, Belo Horizonte destacou-se da expectativa desse acontecimento novo, pois nela percebe-se a condição do saber-se parte do novo, sem, no entanto, desligar-se inteiramente do velho. "A dicotomia antigo e novo marca indelevelmente a história desta cidade. O que surge como radicalmente novo, seja em termos de idéias, posturas e realizações, parece ficar velho no momento seguinte, quando se advoga sua substituição.” (PIMENTEL, 1985, p.61)

Contemporânea ao desenvolvimento e à aplicação de políticas nacionais de valorização e conservação do patrimônio histórico e cultural do país, a criação do Museu Histórico de Belo Horizonte viu-se imbuída do ideário-base de tais políticas. A criação deste museu também se imbuiu da inovadora concepção de nacionalidade pregada pelos modernistas, na qual traços de brasilidade adicionaram à história local valores étnicos e culturais que a engrandeciam de forma peculiar.

\section{Implicações da bipolaridade simbólica do Museu Histórico Abílio Barreto}

Como foi visto aqui, a bipolaridade simbólica do Museu Histórico Abílio Barreto tem origem na década de 1940, época de sua fundação, quando predominavam nos museus brasileiros as idéias do Estado Novo sobre a 
necessidade de preservação do passado glorioso da pátria. Essa visão, oriunda da concepção do Sphan, basicamente destacava a grandiosidade do passado como evidência da materialização dos ideais da nação brasileira, levando, em termos, a um afastamento do cotidiano do homem comum.

Abílio Barreto, mentor e principal administrador do então Museu Histórico de Belo Horizonte, tinha uma visão própria do que deveria ser um museu para a capital mineira. Para ele, era precisamente a aproximação do cotidiano com a história que conferiria sentido à existência do museu. Desse modo, um museu para a cidade de Belo Horizonte deveria traduzir na sua concepção não apenas os ideais republicanos associados à fundação da nova capital, mas também os traços modernistas presentes na sua arquitetura urbana. Sua visão baseava-se na idéia de que a nova capital, recém-construída, deveria ter uma memória que não abandonasse o passado, mas que o reescrevesse criando vínculos com o presente e com o futuro. Daí a necessidade de que o acervo fosse essencialmente uma leitura do novo a partir dos signos do cotidiano. Esses pontos e vista, que eram (e são) antagônicos, levaram à constituição de cenários e lógicas simbólicas específicas para sustentá-los.

À cultura da memória do passado grandioso do Sphan, coube a restauração e ocupação do casarão da antiga Fazenda do Leitão, um prédio do século XVIII que remetia, em seu acervo, ao Curral Del Rei, localidade que precedeu a criação da cidade, herdeira de uma tradição rural que traduz o espírito camponês do homem brasileiro. À cultura da memória "de vanguarda" de Abílio Barreto, coube a percepção da necessidade de se construir um novo edifício, em torno do velho prédio, estabelecendo um contraste claramente perceptível entre o tradicional e o moderno. Esse prédio - só construído na década de 1990, com estrutura em aço, fechamento de concreto e vidro, distribuindo-se por quatro pavimentos com espaços como biblioteca, auditório, a loja do museu e um café-bar aberto ao público - abriga artefatos que remetem à moderna capital mineira, criada para ratificar a inserção da antiga Minas Gerais numa nova era, republicana e moderna.

O que poderia estar circunscrito a uma problemática histórica adquire contornos bastante expressivos para o mundo organizacional, pois como os museus se caracterizam como ambientes propícios ao recolhimento de objetos evocadores de contextos passados, já na seleção, organização e natureza de seu acervo percebe-se o esforço de resgate de um passado intencionalmente buscado. Embora os museus sejam uma reconstituição necessariamente mosaica de contextos passados, cada um deles tem capacidade de enfatizar em si uma idéia nuclear que o situa num campo ideológico definido. Nada mais natural, então, que haja uma coerência por trás de um museu.

No caso do Museu Histórico Abílio Barreto, as matrizes simbólicas de um e de outro ponto de vista estão presentes desde o primeiro momento, fazendo com que haja dois pontos de vista paralelos sobre o que deve ser exposto. O simbolismo organizacional "oficial" (não importa qual seja) e o "contra-simbolismo" (se é que podemos nos referir a ele dessa maneira) digladiam-se num nível tal que passam a influenciar a estrutura física do MHAB, pois, como visto, há dois espaços nitidamente distintos - cada um de acordo com o enfoque apresentado (Sphan ou Abílio Barreto) - e pautas distintas de exposição. Trata-se de um caso peculiar, exemplificando como podem coexistir, conforme suas matrizes específicas de signos e símbolos, dois universos simbólicos na mesma organização.

A escolha deliberada de uma ou de outra matriz simbólica como referência implica, necessariamente, a exclusão de todo o universo de significados da sua concorrente. Isso quer dizer, grosso modo, que toda forma de ver também é uma forma de não ver. A interpretação da realidade, portanto, está (igualmente) no olhar do observador, pois no que tange a organizações culturais como o Museu Histórico Abílio Barreto, há signos propositadamente mobilizados em função de uma experiência específica a que se quer submeter os consumidores culturais. Assim, quem se depara com os artefatos de uma das matrizes simbólicas, entra num mundo particular de significados sugeridos sobre, por exemplo, a ruralidade que precede o caos urbano, sobre os valores da terra subjugados pelo progresso e sobre a grandeza da pátria diluída na densidade demográfica. Nesse mundo particular, os significados também podem ser sugeridos sobre a mudança necessária para resgatar o homem do campo do atraso secular e incutir-lhe os valores impulsionadores de uma nova ordem, mais veloz, mais integrada, e, sobretudo, mais moderna. Nos dois casos, é emitida uma meia mensagem, na qual são parcialmente enfatizados aspectos que retratam a posição oficial sobre o que preservar do passado. 
Cabe aqui questionar: como seria o MHAB se uma matriz simbólica tivesse prevalecido? Haveria uma memória do passado glorioso e rural do Curral Del Rei ou uma visão do moderno e republicano passado recente da capital mineira? Uma ou outra visão teria condições de traduzir a ambigüidade própria da capital de Minas Gerais, um estado ao mesmo tempo rural e urbano, tradicional e contestador? Talvez esteja precisamente nessa indefinição a maior riqueza simbólica do Museu Histórico Abílio Barreto.

No que se refere aos consumidores dos bens culturais, as implicações são de outra ordem: até que ponto conseguem perceber e experimentar o que é proposto pelos artefatos de uma ou de outra matriz simbólica? Conseguiriam identificar e diferenciar claramente o que é oferecido por cada um dos universos simbólicos? E como reagem à intencionalidade simbólica de cada uma das visões? Nesse caso, quando se considera o consumo cultural - uma vez que não existe um comprometimento maior com o acervo, por exemplo -, é de se esperar que o consumidor se posicione de modo ambíguo diante de uma oferta também ambígua. Se o que lhe é apresentado como memória legítima do passado de Belo Horizonte é algo diretamente relacionado a um passado rural perdido ou a uma modernidade urbana recém-encontrada, porque se desfazer de um ou outro ponto de vista? Ambos não poderiam fazer sentido como partes de um quebra-cabeça do que se chama passado? Parece prudente considerar que naturalmente os consumidores tendem a fundir as matrizes simbólicas.

Por fim cabem algumas reflexões sobre possibilidades de desenvolvimento teórico e analítico para os estudos organizacionais a partir da bipolaridade simbólica observada neste caso. Quando se considera que em Belo Horizonte ocorreu uma verdadeira demolição do velho para que fosse erigido o novo, até que ponto não é o que se busca fazer nos estudos organizacionais, com a criação de "novas tradições" em detrimento dos pilares do conhecimento da área? Não se quer dizer com isso que o novo não seja bem-vindo, muito pelo contrário; mas é que muitas vezes se observa, por uma espécie de fetiche da novidade, uma busca desenfreada por idéias "frescas" pouco contaminadas com o que já existe - quando se sabe que, no que concerne a um campo de conhecimento, a "contaminação" é algo recomendável pela consistência teórico-analítica trazida pela proximidade de idéias (REED, 1998).

O caso estudado deixou claro que a história é também uma interpretação, já que aos que cabem escrevê-la ou representá-la, no caso dos curadores de museus, recai o ônus de decidir o que deve ou não ser mostrado, o que deve ou não ser lembrado. Levando em conta a quantidade de abordagens nos estudos organizacionais, não estaríamos lidando com vaidades intelectuais ou com pontos de vista arraigados que pouco contribuem para ampliar perspectivas na área? (FACHIN; RODRIGUES, 1998) Quando as editoras, periódicos e congressos científicos publicam trabalhos que apresentam determinados elementos teóricos, também não optam pelo que deve ser lembrado e pelo que deve ser esquecido? Não seria essa a mais evidente forma de institucionalização (ou de marginalização) de pontos de vista nos estudos organizacionais?

Longe de tentar esgotar essas questões, o que se pretende ao explicitar as implicações da bipolaridade simbólica é sustentar que, quanto à esfera do simbólico, as interpretações (e desdobramentos) possíveis dependem essencialmente do olhar do observador. Ao contrário do tolo relativismo que os críticos do simbolismo insistem em enxergar nessa idéia, o que se abre é um espaço para que a pluralidade se apresente legitimamente no âmbito teórico. Os estudos organizacionais, portanto, deveriam se preocupar menos com o que pretensamente assemelha as abordagens do que com o que as distingue, respeitando, essencialmente, a diferença. 


\section{Referências}

ALVESSON, M. Organization: from substance to image? Organization Studies, Berlin, v.11, n.3, p.373-394, 1990.

; BERG, P. O. Corporate culture and organizational symbolism: an overview. Berlin: De Gruyter, 1992.

ANDRADE, R. F.; MAGALHAES, B. A. A formação da cidade. In: CASTRIOTA, L. B.(Org.). Arquitetura da modernidade. Belo Horizonte: UFMG, 1998.

BAUDRILLARD, J. Da sedução. 3.ed. Campinas: Papirus, 2000.

BERGER, P. L.; LUCKMANN, T. A construção social da realidade. 25.ed. Petrópolis: Vozes, 2005.

BOSI, E. Memória e sociedade: lembranças dos velhos. 3.ed. São Paulo: Companhia das Letras,1994.

BOUDON, R.; BOURRICAUD, F. Dicionário crítico de sociologia. São Paulo: Ática, 1993.

BOURDIEU, P. 0 campo econômico. Campinas: Papirus, 2000.

BULGACOV, S.; BULGACOV, Y. L. M. A construção do significado nas organizações. In: ENCONTRO DE ESTUDOS ORGANIZACIONAIS, II, 2002, Recife. Anais... Recife: Anpad, 2002.

BURRELL, G.; MORGAN, G. Sociological paradigms and organizational analysis. London: Heinemann, 1979.

CARDOSO, C. F. Anais do I Seminário sobre Tempo e História. Rio de Janeiro: Fundação Casa de Rui Barbosa. 1997.

CASTRO, M. C. P. E. Minas: a tessitura imaginária. Análise \& Conjuntura, Belo Horizonte, v.6, n.1, p.116-123, jan./abr. 1991.

CAVEDON, N. R.; FACHIN, R. C. Homogeneidade versus heterogeneidade cultural: um estudo em universidade pública. Organizações \&t Sociedade, Salvador, v.9, n.25, p.61-76, set./dez. 2002.

; FERRAZ, D. L. S. As culturas organizacionais de uma loja autogestionada de economia popular solidária de Porto Alegre. In: ENCONTRO ANUAL DA ASSOCIAÇÃO NACIONAL DE PESOUISA E PÓS-GRADUAÇÃO EM ADMINISTRAÇÃO, XXVIII, 2004, Curitiba. Anais... Curitiba: Anpad, 2004.

CEDOLA, D. Organizações de simbolismo intensivo: o caso Bola de Neve. In: ENCONTRO DE ESTUDOS ORGANIZACIONAIS, III, 2004, Atibaia. Anais... Atibaia: Anpad, 2004.

CHAGAS, M. S. Há uma gota de sangue em cada museu: a ótica museológica de Mário de Andrade. Cadernos de Sociomuseologia, Lisboa, n.13, 1999.

CHAUÍ, M. Brasil: mito fundador e sociedade autoritária. São Paulo: Fundação Perseu Abramo, 2000.

CLARKE III, I.; MICKEN, K. S.; HART, H. S. Symbols for sale...at least for now: symbolic consumption in transition economies. Advances in Consumer Research, Duluth, v.29, n.1, p.25-30, 2002.

DERBAIX, C.; DECROP, A.; CABOSSART, O. Colors and scarves: the symbolic consumption of material possessions by soccer fans. Advances in Consumer Research, Duluth, v.29, n.1, p.511-518, 2002.

FACHIN, R. C.; RODRIGUES, S. B. Nota técnica: teorizando sobre organizações - vaidades ou pontos de vista? In: CLEGG, S.; HARDY, C.; NORD, W. (Org.). Handbook de Estudos Organizacionais. São Paulo: Atlas, 1998. v.1

FREITAS, M. E. A questão do imaginário e a fronteira entre a cultura organizacional e a psicanálise. In: PRESTES MOTTA, F. C.; FREITAS, M. E. (Org.). Vida psíquica e organização. Rio de Janeiro: FGV, 2000.

GIRAUDY, D.; BOUILHET, H. O museu e a vida. Belo Horizonte: UFMG, 1990.

HIRSCH, P. M. Cultural industries revisited. Organization Science, Hanover, v.11, n.3, p.356-361, May/June 2000.

LAMPEL, J.; LANT, T.; SHAMSIE, J. Balancing Act: learning from organizing practices in cultural industries. Organization Science, Hanover, v.11, n.3, p.263-269, May/June 2000.

LAWRENCE, T. B.; PHILLIPS, N. Understanding cultural industries. Journal of Management, London, v.11, n.4, p.430-441, Dec. 2002.

LAZZARATO, M. From capital-labour to capital-life. Ephemera: Theory \& Politics in Organization, v.4, n.3, p.187-203, July/Sep. 2004.

LE GOFF, J. Memória/história. Enciclopédia Einaudi. Porto: Imprensa Nacional/Casa da Moeda, 1984. v.1.

LEACH, E. Cultura e comunicação. Lisboa: Edições 70, 1976.

LIMA, M. E. A. Os paradoxos da "excelência" no mundo do trabalho. In: BIANCO, M. F.; JUNQUILHO, G. S.; WAIANDT, C. (Org.). Tecnologias de gestão: por uma abordagem multidisciplinar. Vitória: Florદtcultura, 2004. 
LINSTEAD, S.; GRAFTON-SMALL, R. Organizational bricolage. In: TURNER, B. A. (Ed.). Organizational Symbolism. New York: De Gruyter, 1990.

LONDRES FONSECA, M. C. 0 patrimônio em processo: trajetória da política federal de preservação no Brasil. Rio de Janeiro: UFRJ/Iphan, 1997.

MAFFESOLI, M. Lógica da dominação. Rio de Janeiro: Zahar, 1978.

MAXWELL, H. Divas of the Wassoulou sound: transformations in the matrix of cultural production, globalization and identity. Consumption, Markets \& Culture, London, v.6, n.1, p.43-53, Jan. 2003.

PIMENTEL, T. V. C. Belo Horizonte ou o estigma da cidade moderna. Varia História, Belo Horizonte, n.18, p.61-68, 1985.

REED, M. Teorização organizacional: um campo historicamente contestado. In: CLEGG, S.; HARDY, C.; NORD, W. (Org.). Handbook de Estudos Organizacionais. São Paulo: Atlas, 1998. v.1.

RODRIGUES, M. V. A. Relações entre o universo simbólico e as práticas cotidianas do trabalho: um estudo em empresas aéreas brasileiras. In: ENCONTRO ANUAL DA ASSOCIAÇÃO NACIONAL DE PESOUISA E PÓS-GRADUAÇÃO EM ADMINISTRAÇÃO, XXIV, 2000, Florianópolis. Anais... Florianópolis: Anpad, 2000.

RODRIGUES, S. B. Fronteiras invisiveis e modernização - formas de ocupação dos espaços simbólicos: implicações para a gerência. In: ENCONTRO ANUAL DA ASSOCIAÇÃO NACIONAL DE PESOUISA E PÓS-GRADUAÇÃO EM ADMINISTRAÇÃO, XX, 1996, Angra dos Reis. Anais... Angra dos Reis: Anpad, 1996.

Cultura corporativa e identidade: desinstitucionalização em empresa de telecomunicações brasileira. Revista de Administração Contemporânea, Curitiba, v.1, n.2, p.45-72, maio/ago. 1997.

SAHLINS, M. Culture and practical reason. Chicago: Chicago University Press, 1976.

SANTOS, M. C. T. M. 0 papel dos museus na construção de uma identidade nacional. In: Anais do Museu Histórico Nacional, Rio de Janeiro, n.28, p.21-36, 1996.

THANEM, T. All that is solid melts into air? Ephemera and the monument. Ephemera: Theory \&t Politics in Organization, v.1, n.1, p.30-35, Jan./Apr. 2001.

WATTANASUWAN, K.; ELLIOT, R. The buddhist self and symbolic consumption: the consumption experience of the teenage Dhammakaya buddhists in Thailand. Advances in Consumer Research, Duluth, v.26, n.1, p.150-155, 1999.

WOOD JR., T. Organizações de simbolismo intensivo. Revista de Administração de Empresas, São Paulo, v.40, n.1, p.20-28, jan./mar. 2000.

Organizações espetaculares. Rio de Janeiro: FGV, 2001. 